Argonne

ANL-ARC-209

\title{
Variable Orifice Design for the ABR-1000 Plant Concept
}

\section{Nuclear Engineering Division}

Any further distribution governments, foreign cr Deputy Assistant Secre may require DOE appre as amended.

\section{NO ACCESS RESTRICTIONS}

This document is not considered OUO-Applied Technology. It was reviewed for Export Controlled Information and found to be suitable for unlimited access and reproduction.

This label reflects Applied Technology instructions issued April 13, 2006, by the the Department of Energy Office of Nuclear Energy. Additional guidance has also been provided by DOE in 2016 and 2018 memos, as well as from NNSA.

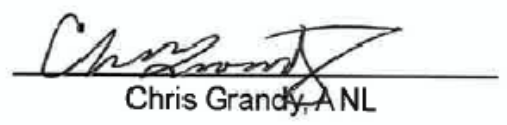

$$
\frac{2 / 15 / 2021}{\text { Date }}
$$

interests, foreign : approved by the reign party release inergy Act of 1954 


\section{About Argonne National Laboratory}

Argonne is a U.S. Department of Energy laboratory managed by UChicago Argonne, LLC under contract DE-AC02-

06CH11357. The Laboratory's main facility is outside Chicago, at 9700 South Cass Avenue, Argonne, Illinois 60439. For information about Argonne, see http://www.anl.gov.

\section{Disclaimer}

This report was prepared as an account of work sponsored by an agency of the United States Government. Neither the United States Government nor any agency thereof, nor UChicago Argonne, LLC, nor any of their employees or officers, makes any warranty, express or implied, or assumes any legal liability or responsibility for the accuracy, completeness, or usefulness of any information, apparatus, product, or process disclosed, or represents that its use would not infringe privately owned rights. Reference herein to any specific commercial product, process, or service by trade name, trademark, manufacturer, or otherwise, does not necessarily constitute or imply its endorsement, recommendation, or favoring by the United States Government or any agency thereof. The views and opinions of document authors expressed herein do not necessarily state or reflect those of the United States Government or any agency thereof, Argonne National Laboratory, or UChicago Argonne, LLC. 
Argonne

ANL-ARC-209

\section{Variable Orifice Design for the ABR-1000 Plant Concept}

\section{T. Farmer and C. Grandy}

Nuclear Engineering Division

Argonne National Laboratory

September 2011

\section{OFFICIAL USE ONLY}

May be exempt from public release under the Freedom of information Act (4 U.S.C. 552), exemption number and category: 5 Privileged Information

Department of Energy review required before public release

Name/Org: Chris Grandy/ANI Date: September 24, 2011 Guidance (if applicable)

\section{Applied Technology-Official Use Only}

Any further distribution by any holder of this product or data therein to third parties representing foreign interests, foreign governments, foreign companies, and foreign subsidiaries or foreign divisions of U.S. companies shall be approved by the Deputy Assistant Secretary for Nuclear Reactor Technologies of U.S. Department of Energy. Further, foreign party release may require DOE approval pursuant to 10CFR810, and/or may be subject to Section 127 of the Atomic Energy Act of 1954 as amended. 


\section{SUMMARY}

The thermal performance of a fast reactor core can be improved by controlling the coolant flow rate in each assembly in order to obtain more uniform assembly exit temperatures, thereby reducing or eliminating the potential for thermal fatigue on Upper Internal Structure. In order for this to occur, the assembly power-to-flow ratio must be held constant across the extent of the core. Traditional fixed-orifice designs provide for step-wise control of flow through the assemblies, but do not allow for in-core adjustments to be made in order to correct mismatches in power-to-flow ratio. In order to accomplish this, it is worthwhile to consider a design for an adjustable orifice within each assembly that can be manipulated during fuel shuffling operations that could optimize power-to-flow ratios and therefore minimize core exit temperature variations. The most practical place for a variable orifice to be installed is at the exit of the fuel assembly so that it can be readily accessed for adjustment during fuel shuffling operations. The purpose of this report was to propose such a variable orifice design for use in advanced fast reactor concepts.

The approach was to modify a variable orifice design that was originally developed and tested in support of the Hallam Nuclear Power Facility (HNPF) located in Nebraska. This design incorporated a tapered plug that moved in and out of a constricted section at the exit of each assembly (essentially an orifice constriction) thereby allowing the flow resistance to be varied by changing the annular flow area. A scaling methodology was used in order to modify the HNPF orifice design for use in current high-power density fast reactor concepts. A scoping design was also developed for a mechanism that could be used to adjust the orifice in-vessel by taking advantage of equipment in the fuel transfer position of the ABR-1000 fast reactor design. A well-instrumented test loop would be a critical element of any program devoted to developing a variable orifice design for advanced fast reactor applications. A simplified design for such a facility was also proposed as part of this study. 


\section{Table of Contents}

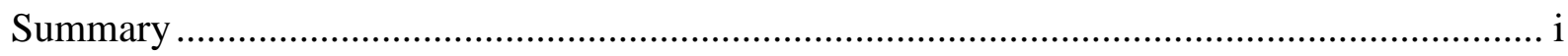

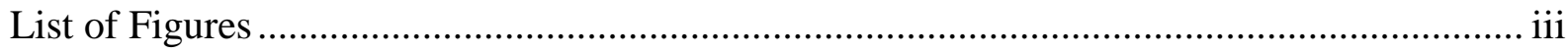

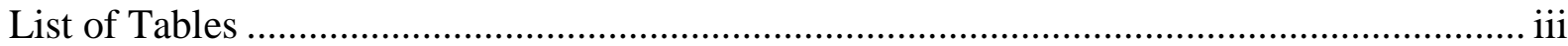

Variable Orifice Design for the ABR-1000 Plant Concept ...................................................5

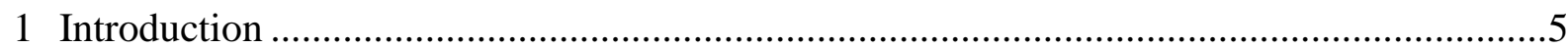

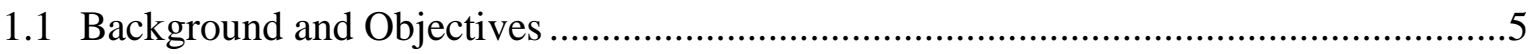

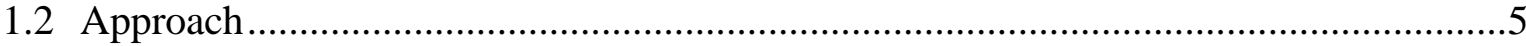

2 Analysis Methodology and Variable Orifice Design Development ...................................7

3 Water Test Loop for Variable Orifice Design Verification .............................................13

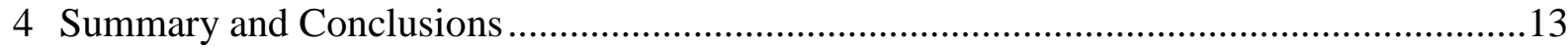

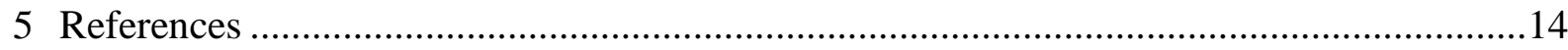




\section{LIST OF FIGURES}

Figure 1. HNPF Fuel Assembly Variable Orifice Design [1] .............................................6

Figure 2. Schematics of Metal and Oxide Duct Designs for ABR-1000 Reference Cores

[2]

Figure 3. Schematic Showing Basic Elements of a Pipe Flow Orifice..................................... 10

Figure 4. Variable Orifice Design for an ABR-1000 Metal Fuel Assembly ............................10

Figure 5. Assembly Pressure Drop without Exit Orifice vs. Assembly Power Level. ............. 12

Figure 6. Assembly Pressure Drop with Exit Orifice vs. Assembly Power Level.....................12

Figure 7. Schematic Illustration of Water Flow Facility for Testing of ABR Test Assembly Orifice Designs........................................................................................ 14

\section{LIST OF TABLES}

Table I: ABR-1000 Fuel Assembly, Pin, and Coolant Channel Flow Data [2]. 



\section{VARIABLE ORIFICE DESIGN FOR THE ABR-1000 PLANT CONCEPT}

\section{Introduction}

\subsection{Background and Objectives}

The thermal performance of a fast reactor core can be improved by controlling the coolant flow rate in each assembly in order to obtain uniform assembly exit temperatures, thereby reducing or eliminating the potential for thermal fatigue on the Upper Internal Structure (UIS). In order for this to occur, the assembly power-to-flow ratio must be held constant across the extent of the core. Traditional fixed-orifice designs provide for step-wise control of flow through the assemblies, but do not allow for in-core adjustments to be made in order to correct mismatches in the power-to-flow ratio. In order to accomplish this, it is worthwhile to consider a design for an adjustable orifice within each assembly that can be manipulated during fuel shuffling operations that could optimize power-to-flow ratios and therefore minimize core exit temperature variations. The most practical place for a variable orifice to be installed is at the exit of the fuel assembly so that it can be readily accessed for adjustment during fuel shuffling operations. The purpose of this report is to propose such a variable orifice design for use in advanced fast reactor concepts. The ABR-1000 was used for this study because its core required more frequent (and traditional) fuel handling than the AFR100 core (a 30-year lived core).

\subsection{Approach}

The approach for accomplishing this objective is to modify a variable orifice design that was originally developed and tested in support of the Hallam Nuclear Power Facility (HNPF) located in Nebraska [1]. This design incorporated a tapered plug that moved in and out of a constricted section at the exit of each assembly (essentially an orifice constriction) thereby allowing the flow resistance to be varied by changing the annular flow area. Two approaches were considered. In the first attempt, a variable orifice was developed that produced a linear change in flow rate as a function of plug position for a fixed $\Delta \mathrm{P}$ across the reactor core. Subsequent studies indicated that this design produced unacceptably large changes in sodium exit temperature for small changes in plug position in some regions of the plug travel, while in other regions a large displacement produced only modest change in temperature. On this basis, a modified design was developed that produced a more uniform change in exit temperature with change in plug position. This second (referred to as Type II in [1]) orifice design is the one that is adopted for modification as part of this work for use in current fast reactor concepts.

The original Type II design developed as part of the Hallam project is shown in Figure 1. As is evident, the concept includes a plug that translates through an orifice plate to effect the adjustment in sodium mass flowrate through the assembly. Guides were incorporated into the fixture to maintain the plug in proper position within the assembly. The mechanical design of the equipment for adjustment of the plug position was not discussed in [1]. Prototype orifice configurations were fabricated and experiments were performed to determine the precise geometry required to obtain the desired flow control. All tests were carried out using water as 
a surrogate for sodium; the results were scaled using dimensional similitude to permit extrapolation of the test results to actual sodium flow conditions in the HNPF core.

The balance of this section describes the methodology by which the HNPF variable orifice design was modified for use in current high-power density fast reactor concepts, as well as a scoping design for the actual fixture that would be deployed in-core. The ABR-1000 (or $\mathrm{ABR}$ ) base core design [2] is used as the starting point for this work.

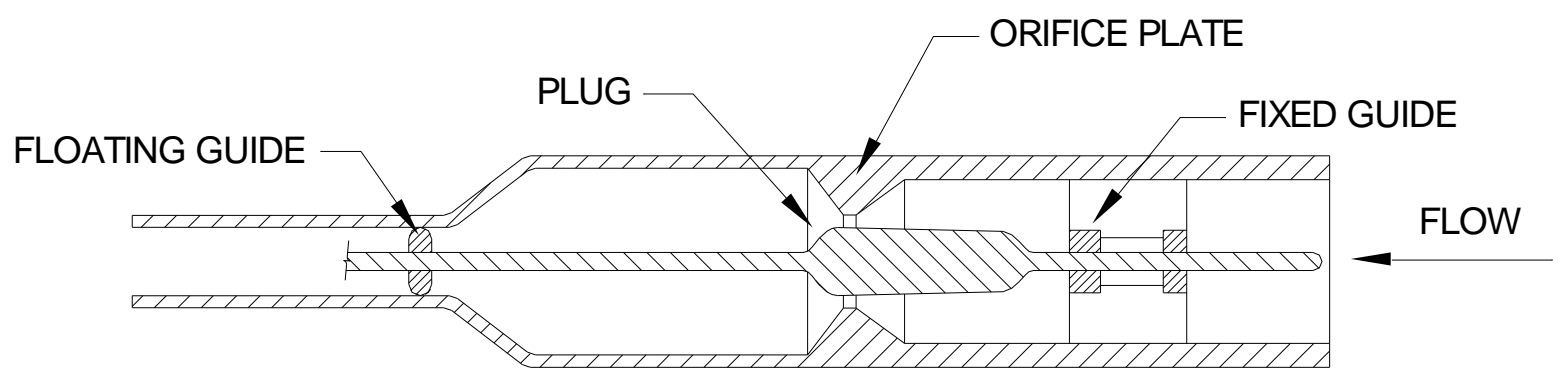

PLUG IN FULLY INSERTED POSITION

Figure 1. HNPF Fuel Assembly Variable Orifice Design [1]. 


\section{$2 \quad$ Analysis Methodology and Variable Orifice Design Development}

The objective of this section is to summarize the methodology by which the HNPF variable orifice design has been adopted for use in the ABR reactor concept [1], and to present the actual design modification for a typical ABR metal core assembly.

The HNPF [1] was a developmental fast reactor that used 19 pin fuel assemblies with a peak sodium mass flowrate of $\sim 10 \mathrm{~kg} / \mathrm{sec}$ through the highest power assemblies. The core pressure drop at full power was nominally $117 \mathrm{kPad}$ (17 psig). In contrast, the ABR fuel assemblies use 271 pins and the peak mass flowrate through the inner high-power core assemblies is nominally $36 \mathrm{~kg} / \mathrm{sec}$. Furthermore, the pressure drop across the core for ABR at full power is $412 \mathrm{kPad}$ (60 psig). For reference, Table I provides core design data used in this study for the ABR, while Figure 2 shows schematics of the assembly designs for both metal and oxide cores [2].

Table I: ABR-1000 Fuel Assembly, Pin, and Coolant Channel Flow Data [2].

\begin{tabular}{|l|c|c|}
\hline \multicolumn{1}{|c|}{ Parameter } & $\begin{array}{c}\text { Metal } \\
\text { Fuel }\end{array}$ & $\begin{array}{c}\text { Oxide } \\
\text { Fuel }\end{array}$ \\
\hline Pins per Assembly & 271 & 271 \\
\hline Total Assembly Length, mm & 4775.2 & 4775.2 \\
\hline Fuel Height, mm & 812.8 & 1066.8 \\
\hline Gas Plenum Height, mm & 1244.6 & 1600.2 \\
\hline Upper Reflector Height, mm & 1117.6 & 635 \\
\hline Lower Reflector Height, mm & 1244.6 & 1117.6 \\
\hline Hydraulic Diameter, mm & 3.361 & 3.361 \\
\hline Coolant Flow Area per Pin, $\mathrm{mm}^{2}$ & 25.03 & 25.03 \\
\hline Empty Duct Cross Sectional Area, $\mathrm{cm}^{2}$ & 189 & 189 \\
\hline
\end{tabular}



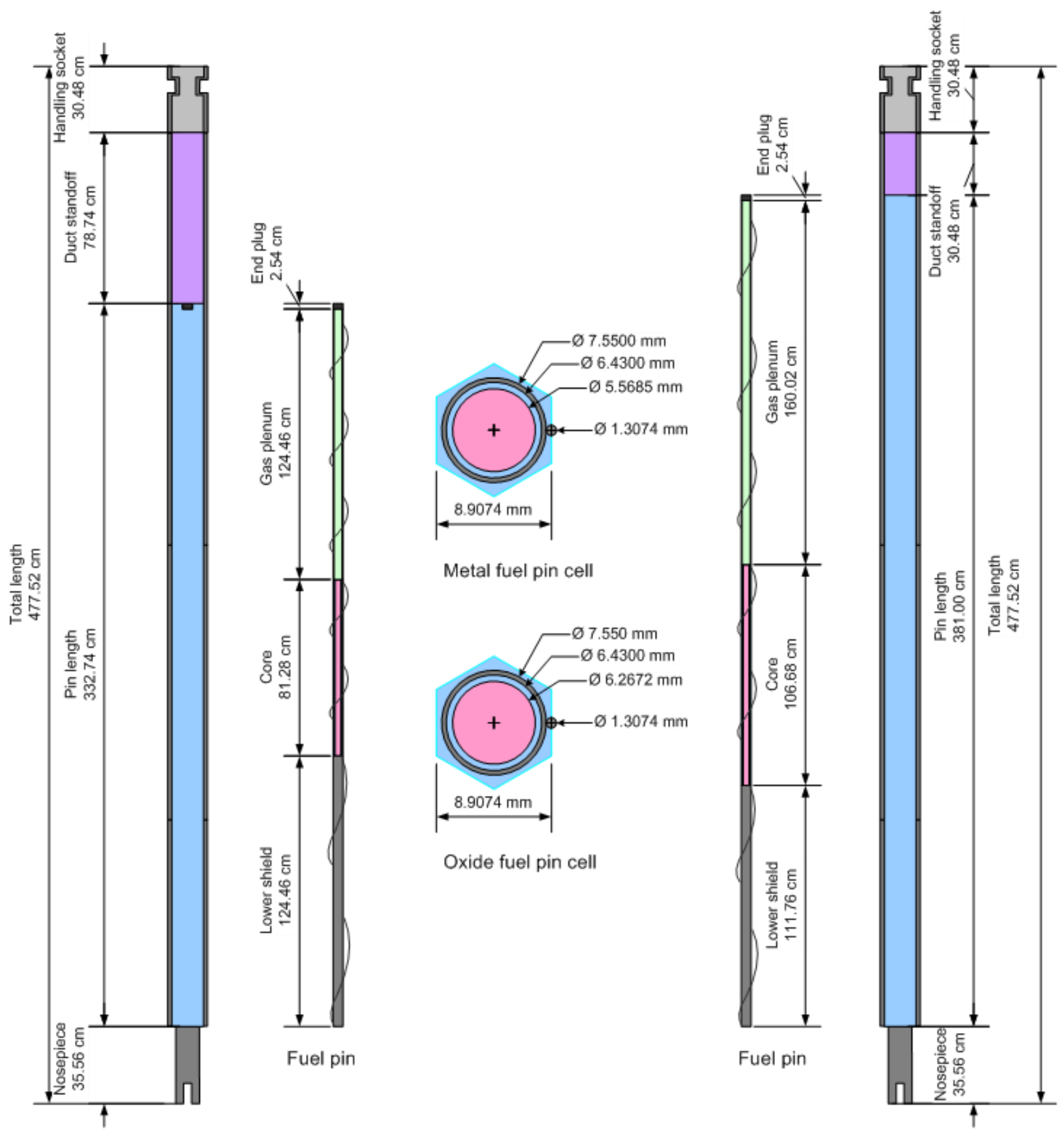

Assembly Duct

Assembly Duct

Metal Fuel

Oxide Fuel

Figure 2. Schematics of Metal and Oxide Duct Designs for ABR-1000 Reference Cores [2].

Given the large variation in core design parameters, a scheme needs to be developed in order to adopt the HNPF variable orifice design to the ABR. To begin, the ABR core is noted to have a relatively high pressure drop relative to the HNPF. Secondly, all orificing for the ABR is accomplished with fixed orifices located at the core inlet, while for HNPF flow was adjusted with the variable orifice shown in Figure 1 located at the core outlet. Due to the 
large design pressure drop for the ABR, a hybrid approach is proposed herein where bulk flow balancing is accomplished at the core inlet using the traditional fixed orifice design, with the variable orifice located at the core outlet to provide fine adjustment capability. The design pressure drop for the Hallam adjustable orifice was $21 \mathrm{kPad}(3 \mathrm{psig})$, which amounts to $5 \%$ of the pressure drop across the ABR core. Moreover, the pressure drop across the HNPF variable orifice could be adjusted by as much as an order of magnitude over the full range of travel $(10 \mathrm{~cm})$. This degree of variation provides more than enough range for fine flow control in the ABR core concept.

The HNPF orifice design is scaled up for use in ABR using dimensional similitude as well as the well known equation that describes pressure drop across an orifice in a pipe; see Figure 3. The equation is of the form:

$$
\Delta P_{\text {orifice }}=\frac{\left(1-\beta^{4}\right) \dot{m}^{2}}{2 \rho C_{d}^{2} A_{\text {orifice }}^{2}}
$$

where

$$
\beta=\frac{D_{\text {orifice }}}{D_{\text {pipe }}}
$$

and $\dot{m}$ is mass flowate, $\rho$ is the fluid density, $C_{d}$ is the velocity coefficient (nominally $0.63)$, and $A_{\text {orifice }}$ is the flow area of the orifice at the constriction. As noted, the orifice design is scaled using dimensional similitude and so it is required that $\beta_{H N P F}=\beta_{A B R}$. Furthermore, the velocity coefficient is taken as relatively constant between the HNPF and ABR design concepts (this is a good assumption). Thus, under the assumption of geometric similitude the relationship between the pressure drop across the ABR and HNPF variable orifices is deduced from Eq. 1 as,

$$
\frac{A_{\text {orifice }, A B R}}{A_{\text {orifice }, H N P F}}=\frac{\dot{m_{A B R}}}{\dot{m}_{H N P F}} \sqrt{\frac{\Delta P_{o r i f i c e, H N P F}}{\Delta P_{\text {orifice }, A B R}}}
$$

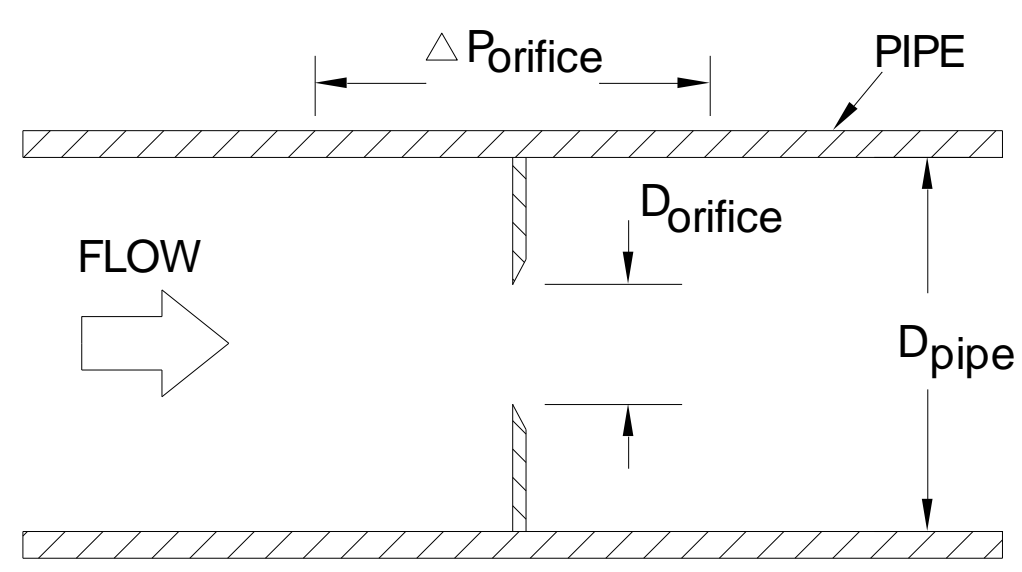


Figure 3. Schematic Showing Basic Elements of a Pipe Flow Orifice.

As noted in the above discussion, it is assumed as a design basis that $\Delta P_{\text {orifice, } H N P F}=$ $\Delta P_{\text {orifice, } A B R} \sim 21 \mathrm{kPad}(3 \mathrm{psig})$. With this last piece of information and the assembly mass flowrates that were stated above (i.e. $10 \mathrm{~kg} / \mathrm{sec}$ in $\mathrm{HNPF}$ and $36 \mathrm{~kg} / \mathrm{sec}$ in ABR), it is thus required that $A_{o r i f i c e, A B R}=3.6 A_{\text {orifice }, H N F}$ from Eq. 3 in order to preserve the pressure drop behavior in ABR relative to the HNPF orifice design and test data. With this requirement and Eq. 2, the area scaling data for the ABR variable orifice are then known.

The ABR variable orifice design that was developed on this basis is provided in Figure 4. The particular design that is shown would occupy the $78.74 \mathrm{~cm}$ (31 inch) duct standoff at the core exit for this particular case (see Figure 1), so that an extension of the overall assembly length would not be required for this particular fuel design. Note in Figure 4 that the design incorporates a simple screw mechanism for adjustment of the orifice position once the assembly is placed in the reactor vessel. The screw engagement nut is at a fixed elevation and is located just below the Fuel Handling Machine (FHM) lifting socket so that modification of this equipment would be required to incorporate the variable orifice design into the $A B R$ concept.

The question arises as to how orifice adjustments would be made once the orificed assemblies are placed in the reactor vessel. It is envisioned that with some minor modifications, the equipment used to transfer fuel into and out of the reactor could be used to make the orifice adjustments. In particular, the fuel transfer position is already configured to receive assemblies and to maintain a steady, well defined coolant flowrate through the assemblies for cooling as the transfer takes place. The fuel gripper that is designed to mechanically attach to the top of the assemblies and remove them from the reactor could be modified to include a screw device for adjusting orifice position once engaged, and a small insitu flowmeter located near the assembly outlet could be used to provide the data required to make the flow adjustment. Of course, additional developmental work would be required in order to work out the technical details before this concept could be deployed.

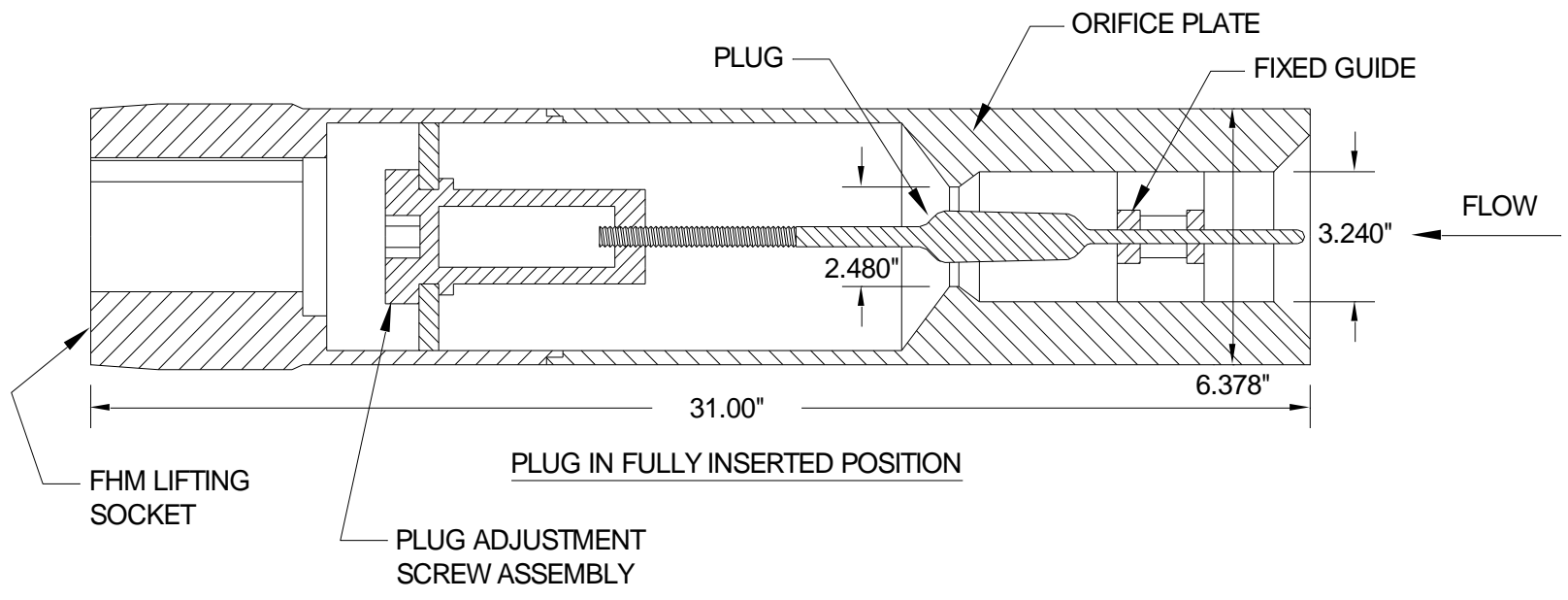

Figure 4. Variable Orifice Design for an ABR-1000 Metal Fuel Assembly 
As noted earlier, the ABR orificing concept utilizes a hybrid approach in which the bulk of the assembly orificing is carried out using the traditional approach at the core inlet, while the variable orifice is used for fine flow control at the outlet. It is worthwhile to investigate the degree to which the inlet orificing would need to be modified in order to incorporate the variable orifice design. Flow pressure drop across the assemblies is calculated using the traditional modified form of the Bernoulli equation, which is of the form:

$$
\Delta P=\left(\sum K+\frac{f L}{D_{H}}\right) \frac{1}{2} \rho U^{2}
$$

where $K$ denotes form loss coefficient, $f$ is friction factor, $L$ is flow length, $D_{H}$ is hydraulic diameter, and $U$ is flow velocity. Substituting Eq. 1 into this expression and making further modifications results in:

$$
\Delta P_{\text {assembly }}=[\underbrace{\frac{1-\beta_{\text {inlet }}^{4}}{C_{d, \text { inlet }}^{2} A_{\text {orific, inlet }}^{2}}}_{\text {inlet orifice }}+\underbrace{\frac{f L}{D_{H}\left(N_{P} A_{P}\right)^{2}}}_{\text {flow friction in bundle }}+\underbrace{\frac{1-\beta_{\text {exit }}^{4}}{C_{d, \text { exit }}^{2} A_{\text {orifice exit }}^{2}}}_{\text {adjustable exit orifice }}+\underbrace{\frac{K_{\text {entrance }}+K_{\text {exit }}}{A_{\text {Duct }}^{2}}}_{\text {entrancelexit form losses }}] \frac{\dot{m}^{2}}{2 \rho}
$$

where $N_{P}$ and $A_{P}$ denote the number of fuel pins and the flow area per pin. The above equation has been labeled in order to identify the pressure loss terms across the various elements of the assembly for future reference. Under full power conditions, flow within the pin bundle is turbulent, and the friction factor is evaluated using the well-known Blasius correlation:

$$
f=0.3164 \mathrm{Re}^{-0.25}
$$

Other thermal-hydraulic input data required to evaluate Eq. 5 is provided in Table I.

The pressure distribution across a standard ABR metal fuel assembly with no exit orificing is shown in Figure 5 as a function of assembly power level. The power range shown in the plot nominally spans the inner and outer core regions for the ABR metal core design. In these two areas there are a total of six different orificing zones [2]. In Figure 5, the required orifice area (i.e., orifice area divided by open duct flow area) required to preserve the power-to-flow ratio is plotted parametrically as a function of power level assuming a core temperature rise of $155 \mathrm{C} \mathrm{[2].} \mathrm{Conversely,} \mathrm{the} \mathrm{same} \mathrm{plot} \mathrm{showing} \mathrm{the} \mathrm{pressure} \mathrm{drop} \mathrm{data}$ across orificed assemblies assuming the nominal orifice pressure drop of $21 \mathrm{kPad}(3 \mathrm{psig})$ at the outlet is provided in Figure 6. As is evident, the pressure drop distributions are very similar, with the only difference being that the inlet orifice size for the assemblies with exit orifices are slightly less constrictive, since part of the pressure loss in this design is born across the outlet orifice. 


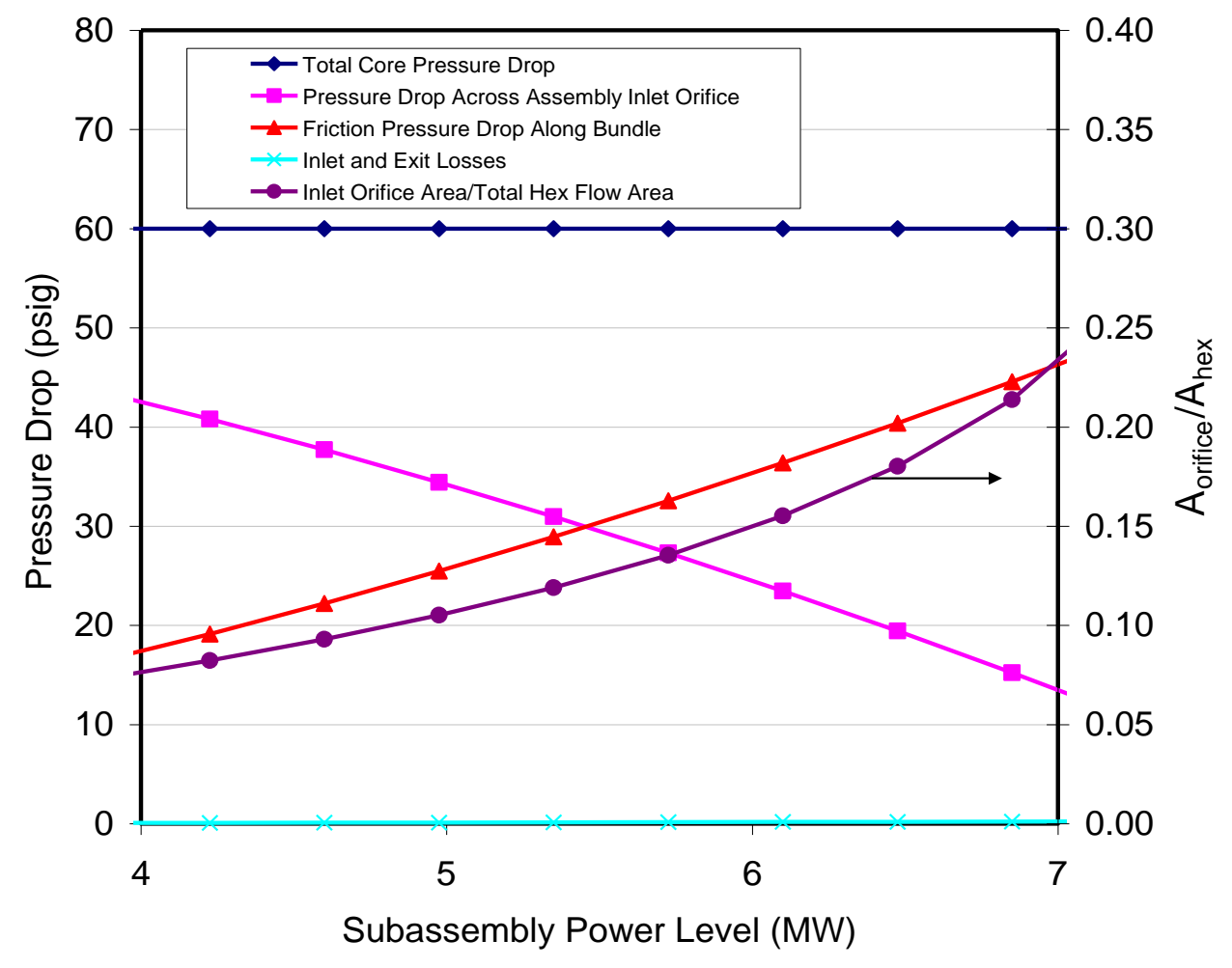

Figure 5. Assembly Pressure Drop without Exit Orifice vs. Assembly Power Level.

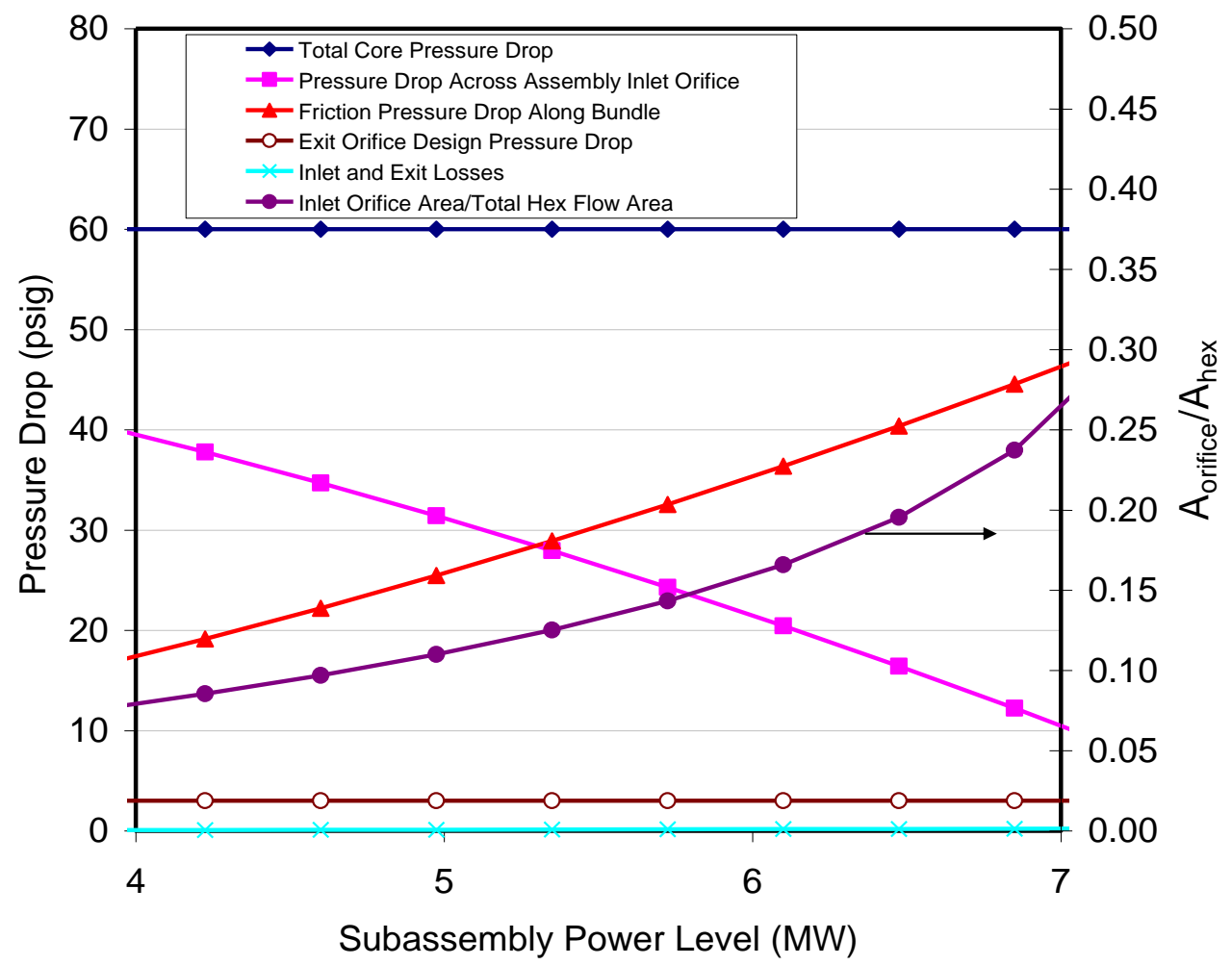

Figure 6. Assembly Pressure Drop with Exit Orifice vs. Assembly Power Level. 


\section{Water Test Loop for Variable Orifice Design Verification}

A highly simplified scaling approach was used in the development of the variable orifice design for the $A B R$. In order to carry out pressure drop verification testing, a simplified water flow loop will be required. A schematic of one such facility, modeled after the one used for the HNPF validation tests, is shown in Figure 7. The loop comprised of two parallel pipe loops attached to a centrifugal pump capable of circulating 44 liters/second (700 gpm) of water at 60 psig pressure drop. The system is arranged so that it can be operated as two parallel loops, each of which contains a flow-metering for placement of an experimental fuel assembly. An immersion heater would be installed in the in-line water storage tank to heat the water inventory and thereby allow the viscosity to be adjusted.

Water is circulated by the pump through a check valve and then into a manifold. From there, the water can be delivered to any combination of the bypass line or the two parallel test loops by adjustment of valves. Water entering the test loops passes horizontally through flow-metering sections and then upwards through the vertical test sections. Thereafter, the water returns through a common downcomer common to the water- storage tank.

A well-instrumented test loop like the one outlined above would be a critical element of any program devoted to developing a variable orifice design for advanced fast reactor applications.

\section{Summary and Conclusions}

The thermal performance of a fast reactor core can be improved by controlling the coolant flow rate in each assembly in order to obtain uniform assembly exit temperatures, thereby reducing or eliminating the potential for thermal fatigue on Upper Internal Structure. In order for this to occur, the assembly power-to-flow ratio must be held constant across the extent of the core. Traditional fixed-orifice designs provide for step-wise control of flow through the assemblies, but do not allow for in-core adjustments to be made in order to correct mismatches in power-to-flow ratio. In order to accomplish this, it is worthwhile to consider a design for an adjustable orifice within each assembly that can be manipulated during fuel shuffling operations that could optimize power-to-flow ratios and therefore minimize core exit temperature variations. The most practical place for a variable orifice to be installed is at the exit of the fuel assembly so that it can be readily accessed for adjustment during fuel shuffling operations. The purpose of this report was to propose such a variable orifice design for use in advanced fast reactor concepts.

The approach was to modify a variable orifice design that was originally developed and tested in support of the Hallam Nuclear Power Facility (HNPF) located in Nebraska. This design incorporated a tapered plug that moved in and out of a constricted section at the exit of each assembly (essentially an orifice constriction) thereby allowing the flow resistance to be varied by changing the annular flow area. A scaling methodology was used in order to modify the HNPF orifice design for use in current high-power density fast reactor concepts. A scoping design was also developed for a mechanism that could be used to adjust the orifice in-vessel by taking advantage of equipment in the fuel transfer position of the ABR-1000 fast reactor design. A well-instrumented test loop would be a critical element of any program devoted to developing a variable orifice design for advanced fast reactor applications. A simplified design for such a facility was also proposed as part of this study. 


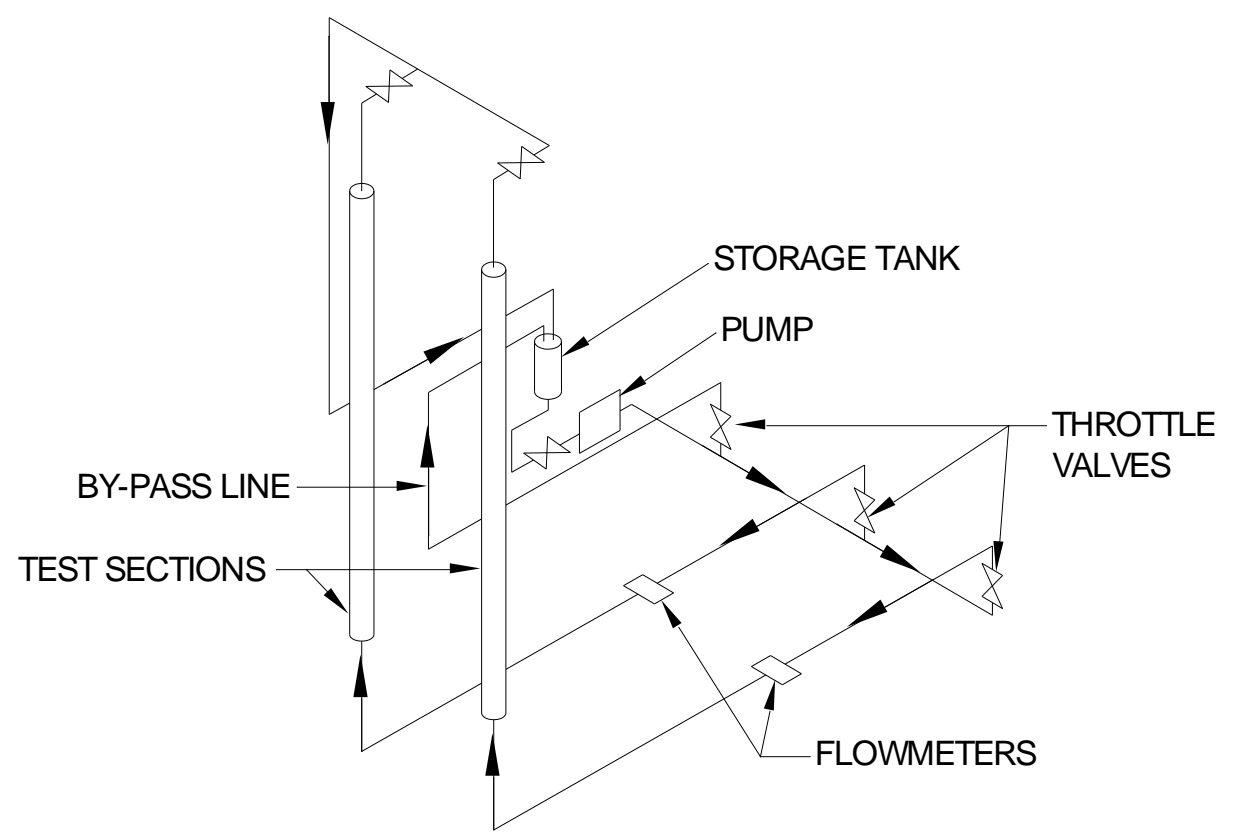

Figure 7. Schematic Illustration of Water Flow Facility for Testing of ABR Test Assembly Orifice Designs.

\section{References}

1. C. J. Baroczy, J. A. Hagel, and W. D. Leonard, "Development of a Variable Orifice for HNPF Fuel Channels,” Atomics International Report NAA-SR-5369, May 1, 1961.

2. C. Grandy et al., "Advanced Burner Reactor 1000MWth Reference Concept," ANLAFCI-202, September 30, 2007. 


\section{Argonne}

\section{Nuclear Engineering Division \\ Argonne National Laboratory \\ 9700 South Case Avenue}

Argonne, IL 60439

www.anl.gov

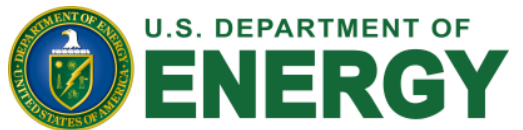

Argonne National Laboratory is a U.S. Department of Energy

laboratory managed by UChicago Argonne, LLC 